TITLE:

\title{
Facile preparation of transparent monolithic titania gels utilizing a chelating ligand and mineral salts
}

\section{$\operatorname{AUTHOR}(\mathrm{S}):$}

Hasegawa, George; Kanamori, Kazuyoshi;

Nakanishi, Kazuki; Hanada, Teiichi

\section{CITATION:}

Hasegawa, George ... [et al]. Facile preparation of transparent monolithic titania gels utilizing a chelating ligand and mineral salts. Journal of Sol-Gel Science and Technology 2010, 53(1): 59-66

\section{ISSUE DATE:}

2010-01

URL:

http://hdl.handle.net/2433/97924

\section{RIGHT:}

c 2009 Springer Science+Business Media, LLC.; この論文は出版社版で ありません。引用の際には出版社版をご確認ご利用ください。; This is not the published version. Please cite only the published version. 


\section{Facile Preparation of Transparent Monolithic Titania Gels Utilizing a Chelating Ligand and Mineral Salts}

Joji Hasegawa, Kazuyoshi Kanamori,* Kazuki Nakanishi, Teiichi Hanada

Department of Chemistry, Graduate School of Science, Kyoto University

Kitashirakawa, Sakyo-ku, Kyoto 606-8502, JAPAN.

TEL: +81757537673

FAX: +81 757537673

E-mail: kanamori@kuchem.kyoto-u.ac.jp

\section{ABSTRACT}

Highly homogeneous transparent titania gels have been successfully prepared from titanium alkoxide by a sol-gel method utilizing chelating agent, ethyl acetylacetate (EtAcAc), in the presence of strong acid anions. Only catalytic amount of a strong acid anion suppress the rapid hydrolysis of titanium alkoxide by blocking the nucleophilic attack of $\mathrm{HO}^{-}$and $\mathrm{H}_{2} \mathrm{O}$, and the resultant moderate sol-gel reactions thus afford homogeneous gelation, leading to transparent monolithic titania gels. Gelation time can be widely controlled by changing amounts of water, chelating agent and salt. The ability of salts to suppress the too abrupt sol-gel reactions is strongly dependent on the electronegativity of anions and valence of cations. With employing $\mathrm{NH}_{4} \mathrm{NO}_{3}$ as a suppressing electrolyte, the obtained titania gels can be converted to pure $\mathrm{TiO}_{2}$ by simple washing and heat-treatment, and transformations to anatase and rutile structures were found to start at 400 and $600{ }^{\circ} \mathrm{C}$, respectively. 
Keywords :titania gels, titanium alkoxide, chelating agent, mineral salts, monolithic gels, crystallization

Abbreviation

Transparent Monolithic Titania Gels Utilizing Ligand and Salts

\section{Introduction}

Titanium dioxide, $\mathrm{TiO}_{2}$, has received much attention as material for many applications in the field of separation media [1-3], catalysts [4-6] and electrodes [7-11] due to its unique physical and chemical properties, such as high refractive index, high dielectric constant and photocatalytic activities [12, 13]. For the higher performance of these applications, it is necessary to control the material shape of $\mathrm{TiO}_{2}$ into desired ones such as powder, fibers, films and monoliths. To achieve this flexible control of shapes, sol-gel reactions based on titanium alkoxides have been widely investigated and preparations of $\mathrm{TiO}_{2}$ powders and films have been widely reported [14-18]. There are also reports on the preparation of monolithic titania composite systems such as $\mathrm{TiO}_{2}-\mathrm{SiO}_{2}$ [19-22]. However, it is well known that pure $\mathrm{TiO}_{2}$ monoliths are difficult to synthesize by the sol-gel method due to the too high reactivity of titanium alkoxides. The Ti atoms in titanium alkoxide $\mathrm{Ti}(\mathrm{OR})_{4}$ is too susceptible to the nucleophilic attack of water or other nucleophilic molecules because of the relatively large difference of electronegativity between $\mathrm{Ti}$ and $\mathrm{O}$ which makes $\mathrm{Ti}$ have more positive partial charge, and of coordinatively unsaturated valence state of $\mathrm{Ti}$ which allows nucleophilic addition to stabilize into the octahedral coordination. The too high reactivity makes it difficult to form monolithic gels which require homogeneous gelation of the whole starting solution by the moderate progress of 
polycondensation. In other words, titanium alkoxides with too high reactivity normally form particles and precipitate in the reacting solution.

Yoldas prepared titania gel monoliths from titanium alkoxide by the sol-gel method under strongly acidic conditions for the first time [23]. After that, there were some reports on the preparation of alkoxide-derived sol-gel titania gel monoliths by using strong acid [24, 25]. This method utilizes electrostatic repulsion to suppress the rapid condensation, i.e. protonated hydroxyl groups in the hydrolyzed titanium alkoxide hinder the nucleophilic attack toward positively charged Ti ions in such conditions. In addition, alkoxy-derived oligomers grown by the gradual condensation are positively charged as well and stabilized by the electrostatic repulsion. However, the use of strong acids is indispensable in this method. Therefore, it was impossible to prepare titania gels in a metal vessel and titania films on a metal substrate by this method. In another report, slow hydrolysis was achieved by slowly providing water for hydrolysis which is generated as the by-product of a slow esterification reaction between carboxylic acid and alcohol [26, 27]. This method does not require the strong acids, however, it takes substantial time (10-100 h) to obtain a transparent monolithic gel. Therefore, the better control of the homogeneous gelation of titanium alkoxide in a milder condition has been strongly desired.

In this work, we tried to prepare transparent titania gels in a nearly neutral condition by the sol-gel method utilizing a chelating agent which coordinates with titanium alkoxide to attain the better control of the gelation. The chelating method has been utilized to slow down the hydrolysis and to prepare titania films and glass composites [28-30]. However, in our preliminary experiments, this method employing ethyl acetylacetate (EtAcAc) has been proved to be inadequate for obtaining monolithic gels since the precursor sol must be concentrated to 
obtain monolithic gels and in such a concentrated sol, the reaction was too abrupt to be adequately controlled. In addition to the use of the chelating agent, we found that only catalytic amounts of some kinds of simple anions are significantly effective to obtain transparent titania gels by well-controlled hydrolysis and condensation reactions. Moreover, the gelation time is typically only a half or a few hours and can be widely controlled by varying the starting compositions. There are some reports on that anions affect the evolving particle morphology and stability in the sol-gel systems by competing with aquo ligands for coordination to the metal centers [31]. In addition, Mir et al. tailored transparent monolithic titania gels in the presence of $\mathrm{PrCl}_{3} \cdot \mathrm{H}_{2} \mathrm{O}$ to dope $\mathrm{Pr}^{3+}$ in titania gel monoliths [27]. However, in their method, the water for hydrolysis was released by esterification of acetic acid with methanol and from $\operatorname{PrCl}_{3} \cdot \mathrm{H}_{2} \mathrm{O}$. In our method, the sol-gel reaction of titanium alkoxide can be triggered by the simple addition of an aqueous solution of mineral salt. In this report, the reaction mechanism including the role of anions in the sol-gel reaction is discussed by investigating the relationship between the starting compositions and the gelation behaviors such as gelation time and the appearances of the resultant monolithic gels. The chelating agent and anions can be removed by simple heat treatment and the titania gels can be crystallized into anatase and rutile $\mathrm{TiO}_{2}$.

\section{Experimental}

The reagents used in this study are titanium (IV) $n$-propoxide (Ti(OPr) ${ }_{4}$, SigmaAldrich Co. (USA)), 1-propanol (PrOH, Tokyo Chemical Industry Co., Ltd. (Japan)), ethyl acetylacetonate (EtAcAc, Tokyo Chemical Industry Co., Ltd. (Japan)) and various mineral salts. $\left(\mathrm{NH}_{4}\right)_{2} \mathrm{VO}_{3},\left(\mathrm{NH}_{4}\right)_{2} \mathrm{HPO}_{4}, \mathrm{KCl}, \mathrm{KNO}_{3}$ and 
$\mathrm{AlPO}_{4}$ were purchased from Wako Pure Chemical Industries Ltd. (Japan). $\mathrm{K}_{2} \mathrm{SO}_{4}$ and $\mathrm{K}_{2} \mathrm{CO}_{3}$ were purchased from Hayashi Pure Chemical Industry Ltd. (Japan). $\mathrm{CaCl}_{2}, \mathrm{AlCl}_{3}, \mathrm{FeCl}_{3}, \mathrm{YCl}_{3}, \mathrm{LaCl}_{3}$ and $\mathrm{CeCl}_{3}$ were purchased from Sigma-Aldrich Co. (USA). Other mineral salts were obtained from Kishida Chemical Co., Ltd. (Japan). All chemicals were used as received without further purification.

First, given amounts of $\mathrm{Ti}(\mathrm{OPr})_{4}, \mathrm{PrOH}$ and EtAcAc were mixed in a glass tube in the listed order. After stirring for $30 \mathrm{~min}$, the transparent light yellow solution was ice-cooled followed by slowly addition of various aqueous solutions of salts. After stirring for $5 \mathrm{~min}$ at $0{ }^{\circ} \mathrm{C}$, the obtained yellow solution was left at $40{ }^{\circ} \mathrm{C}$ in an oil bath to allow gelation. The obtained gels were dried at $60{ }^{\circ} \mathrm{C}$ for $48 \mathrm{~h}$. The gelation time was defined when solution loses fluidity.

Thermal analysis (TG-DTA) was performed on the dried sample with Thermo plus TG 8120 (Rigaku Corp., Japan) at a rate of $5^{\circ} \mathrm{C} \cdot \mathrm{min}^{-1}$ while continuously supplying air at a rate of $100 \mathrm{~mL} \cdot \mathrm{min}^{-1}$. The X-ray diffraction patterns of the samples were recorded by RINT-Ultima III (Rigaku Corp., Japan) with Cu Ka radiation. The FT-IR spectra were recorded on FTIR-8300 (Shimadzu, Japan) using ground samples which were mixed with $\mathrm{KBr}$ to give a $2 \mathrm{wt} \%$ sample. A total of 100 scans were recorded with a resolution of $2 \mathrm{~cm}^{-1}$.

\section{Results}

Table 1 shows the obtained titania gel appearances prepared with various mineral salts. It was found that transparent titania gels were obtained in the presence of $\mathrm{Cl}^{-}, \mathrm{Br}^{-}, \mathrm{I}^{-}$and $\mathrm{NO}_{3}{ }^{-}$and that the cation types gives almost no influence on the obtained gel appearance. Except for the fluoride and sulfate 
salts, strong acid salts influence the reaction while weak acid salts have no influence on the reaction.

Table 2 shows the gelation time of $\mathrm{Ti}(\mathrm{OPr})_{4}$ prepared in the presence of various chloride salts at the same concentration of chloride anions. It is found that there is a little difference among the gelation times. The gelation time increases in the order of $\mathrm{KCl}<\mathrm{CaCl}_{2}<\mathrm{AlCl}_{3}$. In the case of $\mathrm{NH}_{4} \mathrm{Cl}$, the gelation time was somewhat longer than $\mathrm{KCl}$ and nearly equal to $\mathrm{CaCl}_{2}$. Next, the effect of various anions on the gelation of $\mathrm{Ti}(\mathrm{OPr})_{4}$ was investigated by using various potassium salts at the same concentration of anions shown in Table 3. It is found that the gelation time became longer in the order of $\mathrm{I}^{-}<\mathrm{Br}^{-}<\mathrm{Cl}^{-}<\mathrm{NO}_{3}^{-}$. Comparing Table 2 with Table 3, it was found that the anions have a larger effect on the gelation time than cations.

Figure 1 shows the relationship between the gelation time and the concentration of the aqueous solutions of $\mathrm{NH}_{4} \mathrm{Cl}$. The gelation time became longer with increasing concentration of $\mathrm{NH}_{4} \mathrm{Cl}$. Moreover, the gelation time is nearly proportional to the concentration of $\mathrm{NH}_{4} \mathrm{Cl}$ aq. and peaks out at around $2.5 \mathrm{~mol} \%$ of $\mathrm{NH}_{4} \mathrm{Cl}$.

The effect of the amount of EtAcAc on the gelation time is shown in Figure 2 and Table 4. In this study, the amount of EtAcAc increased with simultaneously decreasing the amount of $\mathrm{PrOH}$ to equalize the volume of the whole solutions. It is found that the gelation time became longer as the amount of EtAcAc increased. However, in the compositions with relatively large amounts of EtAcAc, the gelation time became a little shorter. This is because EtAcAc acts only as a bidentate ligand and excess EtAcAc gives no effect on the gelation behavior. Moreover, the large amounts of EtAcAc make the solubility of $\mathrm{H}_{2} \mathrm{O}$ poorer and 
the hydrolysis occurs more rapidly as soon as $\mathrm{H}_{2} \mathrm{O}$ is added whereas the reason is unknown.

The effect of the amount of $\mathrm{H}_{2} \mathrm{O}$ on the gelation is shown in Figure 3 . It should be noted that the gelation time dramatically increased with decreasing the amount of $\mathrm{H}_{2} \mathrm{O}$. In addition, when only 2.5 equivalent of $\mathrm{H}_{2} \mathrm{O}$ to $\mathrm{Ti}(\mathrm{OPr})_{4}$ was added, the gelation did not occur in a couple of weeks.

Figure 4 shows the appearance of the obtained gels prepared with different amounts of $\mathrm{NH}_{4} \mathrm{Cl}$. Addition of only $0.5 \mathrm{~mol} \%$ of $\mathrm{NH}_{4} \mathrm{Cl}$ to $\mathrm{Ti}(\mathrm{OPr})_{4}$ enables to obtain almost transparent titania gels and $0.75 \mathrm{~mol} \%$ of $\mathrm{NH}_{4} \mathrm{Cl}$ is enough to obtain highly homogeneous titania gels. Figure 5 shows the TG-DTA curves of the dried gels. In order to identify the weight decreases and the exothermal peaks, the dried samples prepared from different concentration of EtAcAc were investigated. The weight decrease at around $400{ }^{\circ} \mathrm{C}$ increases with increasing amounts of EtAcAc. In addition, the X-ray diffraction (XRD) patterns and FTIR spectra of the heat-treated samples were also obtained to investigate the reaction of the gels during the heat-treatment as shown in Figure 6 and Figure 7, respectively. According to the XRD patterns shown in Figure 6, the samples heat-treated below $300{ }^{\circ} \mathrm{C}$ were identified as being in the X-ray amorphous state. After the heat-treatment at 400 and $500{ }^{\circ} \mathrm{C}$, the samples exhibit XRD patterns of the anatase crystal structure. The XRD patterns of rutile phase starts to appear in the sample heat-treated at $600{ }^{\circ} \mathrm{C}$ and only the $\mathrm{XRD}$ patterns of rutile phase is observed at $700{ }^{\circ} \mathrm{C}$. In Figure 7, the absorption bands at 2349 and $667 \mathrm{~cm}^{-1}$ are attributed to carbon dioxide in air. The infrared spectrum of the dried gel indicates that there are several bands around 1610, 1530, 1430 and $1280 \mathrm{~cm}^{-1}$ (marked with "○”) which can be attributed to the vibrations of acetylacetate groups coordinated to $\mathrm{Ti}$ [32]. In addition, the stretching vibrations of $\mathrm{O}-\mathrm{C}-\mathrm{C}$ in 
alkoxy groups are also observed at 1120, 1080 and $1000 \mathrm{~cm}^{-1}$. After the heattreatment at 200 and $300{ }^{\circ} \mathrm{C}$, the vibrations of acetylacetate groups coordinated to Ti remain around 1515 and $1410 \mathrm{~cm}^{-1}$, whereas the vibrations of O-C-C disappear due to the pyrolysis of ester and the burn-off of the propoxide groups.

\section{Discussions}

The chelating agent EtAcAc is known to make complex with Ti by donating oxygen lone pairs to the empty d orbital of $\mathrm{Ti}$ and reduce the hydrolysis rate of titanium alkoxide [33]. However, not homogeneous transparent titania gels but opaque gels are obtained by hydrolysis and polycondensation reactions even in the existence of EtAcAc due to the significantly rapid condensation reaction after hydrolysis. Therefore, the acid anions, $\mathrm{I}^{-}, \mathrm{Br}^{-}, \mathrm{Cl}^{-}$and $\mathrm{NO}_{3}{ }^{-}$, play an important role in the homogeneous gelation observed in this study. According to the previous reports [27], it was supposed that the chloride anions participate in the $\mathrm{Ti}$ complexation or act as a Lewis base catalyst for sol-gel condensation but there was no further investigation. Therefore, here we discuss the role of anions in the gelation of $\mathrm{Ti}(\mathrm{OPr})_{4}$ as follows.

The sol-gel reaction of titanium alkoxide includes two steps; hydrolysis of titanium alkoxide and polycondensation. In the co-presence of EtAcAc, titanium alkoxide is chelated as shown in Scheme 1 and hence the hydrolysis is suppressed. Therefore, when $\mathrm{H}_{2} \mathrm{O}$ was added to the mixture of titanium alkoxide and EtAcAc, we can obtain homogeneous clear yellow solution with avoiding the abrupt progress of hydrolysis and polycondensation of titanium alkoxide. However, the chelated titanium alkoxide is still susceptible enough to be hydrolyzed and polycondensed, and resulted in the formation of relatively large particles as shown 
in Figure 4 (a) though the obtained gel is monolithic. The hydrolyzed and partially condensed $\mathrm{Ti}$ atoms become more reactive to nucleophilic attack than the sites where $\mathrm{Ti}$ atoms are less hydrolyzed and condensed because the former is more electron deficient than the latter [34]. Then, the reaction takes place locally and heterogeneously, i.e. hydrolyzed and condensed species continue to react more whereas unreacted species remain. On the other hand, in the presence of both EtAcAc and strong acid anions, homogeneous and transparent titania gels are obtained as shown in Figure 4 (d). It can be deduced that strong acid anions suppress either hydrolysis or polycondensation, or both of them. Taking into consideration that the amount of $\mathrm{H}_{2} \mathrm{O}$, which triggers and governs hydrolysis, makes the most important contribution to the gelation time as shown in Figure 3, the anions mainly affect the hydrolysis step. This is because the amount of $\mathrm{H}_{2} \mathrm{O}$ would have only slight effect on the gelation time if anions suppressed only the slower polycondensation step. In addition, Figure 1 indicates that the gelation time is nearly in proportion to the amount of anions. These results strongly suggest that the strong acid anions play a role of the ligand coordinated to $\mathrm{Ti}$ atoms and prevent the nucleophilic attack of $\mathrm{HO}^{-}$and $\mathrm{H}_{2} \mathrm{O}$. Taking into consideration that only $0.75 \mathrm{~mol} \%$ of $\mathrm{NH}_{4} \mathrm{Cl}$ relative to $\mathrm{Ti}(\mathrm{OPr})_{4}$ was enough to obtain transparent titania gels, we propose the whole reaction mechanism as follows. First, $\mathrm{Ti}(\mathrm{OPr})_{4}$ chelated with EtAcAc is hydrolyzed to some extent and the polycondensation starts as soon as the aqueous solution of salt is added as shown in Scheme 2 [34, 35]. This mechanism is supported by the fact that the color of sol changes from light yellow to dark yellow (the similar color as the resultant gel) as soon as the aqueous solution is added. The surface of the resultant oligomers is surrounded by EtAcAc by making complexes with leaving considerable unreacted alkoxy groups. Without the strong acid anions, the more 
hydrolyzed and condensed $\mathrm{Ti}$ atoms are more susceptible to further hydrolysis as described above. On the other hand, with the strong acid anions, Ti atoms can be coordinated by the anions and are stabilized in the form of 6-coordinate complex. The more hydrolyzed and condensed $\mathrm{Ti}$ atoms are more effectively coordinated by strong anions. Then, those sites become inert against further hydrolysis and condensation. The coordinating strong acid anions, however, decoordinate after a short period of time due to their poor electron-donating ability, i.e. the chemical bond between $\mathrm{Ti}$ and the anions should be highly ionic. The decoordinated anion attaches to another $\mathrm{Ti}$ atom and dissociates again after a short period of time. In this way, strong acid anions diffusively move from one $\mathrm{Ti}$ atom to another and continue to coordinate and decoorinate in the condensating system as simply shown in Scheme 3. Thus, anions can be regarded as a moderate suppressing agent of hydrolysis. The Ti atoms which are not temporally coordinated with anions will undergo prompt hydrolysis and soon stop reacting when being coordinated again. As a whole, the hydrolysis of titanium alkoxide gradually occurs in the presence of catalytic amount of the strong acid anions.

Based on the mechanism as described above, the reason why some anions cannot suppress the hydrolysis reaction is explained. In the case of the weak acid salts, one of the reasons for the lack of the suppression ability is that the amount of dissociated weak acid anions is too small. The weakly basic condition of the aqueous solution of weak acid salt should be another reason because the hydrolysis of titanium alkoxide takes place more rapidly in alkaline solution. In the case of $\mathrm{SO}_{4}{ }^{2-}$, which is known to coordinate to $\mathrm{Ti}$ atoms [36, 37], polycondensation is accelerated and resulted in heterogeneous opaque titania gels which are partially sulfated. Meanwhile, $\mathrm{F}^{-}$is well-known to strongly interact with $\mathrm{TiO}_{2}$ and $\equiv \mathrm{Ti}-\mathrm{OH}$ is replaced by $\equiv \mathrm{Ti}-\mathrm{F}$ at lower $\mathrm{pH}$ range (i.e. at 3-4) [38, 
39]. Although $\mathrm{F}^{-}$leaves $\mathrm{Ti}$ atom when the $\mathrm{pH}$ value changes to basic condition (i.e. to 8-9), in this study, most of the $\mathrm{F}^{-}$coordinate $\mathrm{Ti}$ atoms because of a little acidic condition. Therefore, the amount of dissociated $\mathrm{F}^{-}$is too small to have an effect on the gelation of titanium alkoxide.

The strength of the retarding effects of the sol-gel reaction with different anions can be explained by the electronegativities of anions. The larger electronegativity makes the anions more effectively coordinate to Ti atoms and more strongly suppresses the hydrolysis by establishing the stable 6-coodination state. Among nitrate and halogen anions, the order of the electronegativity is $\mathrm{I}^{-}$ $<\mathrm{Br}^{-}<\mathrm{Cl}^{-}<\mathrm{NO}_{3}^{-}[40,41]$ and the observed order of the gelation time was $\mathrm{I}^{-}<$ $\mathrm{Br}^{-}<\mathrm{Cl}^{-}<\mathrm{NO}_{3}{ }^{-}$, which is consistent with the order of electronegativity.

Compared to the anions species, the cation species have little effect on the gelation behavior of $\mathrm{Ti}(\mathrm{OPr})_{4}$ as shown in Table 2 . The little difference of the gelation time in the presence of various chloride salts is attributed to the difference of the cation valence and the cation concentration. However, since the considerably small amount of salts was used in this study, the decrease of the amount of free water available for hydrolysis by the hydration to cations is vanishingly small. Similarly, since the anion/water ratio is also considerably small, the hydration of water both to cations and anions should not cause a large effect on hydrolysis and condensation.

The networks of the resultant titania gels still include the sites chelated by EtAcAc according to the FT-IR spectrum of the dried gel as shown in Figure 7. The TG curves show two weight decreases above $400{ }^{\circ} \mathrm{C}$, which is attributed to the combustion of organic compounds, residual hydroxyl and alkoxy groups and EtAcAc ligands. The weight decrease below $300{ }^{\circ} \mathrm{C}$ is attributed to the removal of physically absorbed water and solvent. It is found that the weight decrease at 
$400{ }^{\circ} \mathrm{C}$ increases as the amount of EtAcAc increases, whereas the weight decrease at $500{ }^{\circ} \mathrm{C}$ is almost constant among the samples. This indicates that the coordinated EtAcAc was decomposes at $400{ }^{\circ} \mathrm{C}$. The disappearance of the absorption bands attributed to the acetylacetonate group coordinated to $\mathrm{Ti}$ in the infrared spectrum of the sample heat-treated above $400{ }^{\circ} \mathrm{C}$ agrees with this assumption. Taking into the account the fact that the XRD patterns of anatase structure appear at $400{ }^{\circ} \mathrm{C}$ as shown in Figure 6, the ligands are pyrolyzed at $400{ }^{\circ} \mathrm{C}$ and simultaneously the phase transition from the amorphous to anatase occurs. The fact that there is no obvious change among the infrared spectra of the samples heat-treated above $400{ }^{\circ} \mathrm{C}$ indicates that the weight decrease of the TG curves at $500{ }^{\circ} \mathrm{C}$ in Figure 5 derives from the complete degradation of pyrolyzed products (such as char) from coordinated EtAcAc and propoxide groups, and from water release by the additional condensation to form Ti-O-Ti bonds.

\section{Conclusions}

Highly homogeneous monolithic titania gels are easily obtained by the sol-gel reaction of titanium propoxide, $\mathrm{Ti}(\mathrm{OPr})_{4}$, in the presence of a chelating agent, EtAcAc and strong acid anions such as $\mathrm{Cl}^{-}, \mathrm{Br}^{-}, \mathrm{I}^{-}$and $\mathrm{NO}_{3}{ }^{-}$. The strong acid anions are deduced to play a role of blocking agents which prevent $\mathrm{Ti}$ atoms from being exposed to nucleophilic reactions. The anions such as $\mathrm{SO}_{4}{ }^{2-}, \mathrm{F}^{-}$and those from weak acid salts are not effective for separate reasons. The gelation time of $\mathrm{Ti}(\mathrm{OPr})_{4}$ can be extensively controlled in high reproducibility by varying the starting compositions. To slow down the gelation, there are some methods such as increasing the amount of EtAcAc, increasing the concentration of anions and 
decreasing the amount of $\mathrm{H}_{2} \mathrm{O}$. The obtained titania gels include EtAcAc ligands even after drying. The phase transition from amorphous to anatase occurs at around $400{ }^{\circ} \mathrm{C}$ and that from anatase to rutile occurs at around $600{ }^{\circ} \mathrm{C}$.

Systematic studies on effects of anions by using a series of mineral salts to obtain transparent monolithic titania gels have not been reported so far, whereas effects of anions on ferric hydrous oxide have been investigated to obtain welldefined particle in the classical work as mentioned above [31]. Compared to other reported methods of preparing transparent monolithic gels, the present method possesses advantages of being free from the strong acid conditions, and being more facile and convenient because of the shorter and easily controllable gelation times. Also, by utilizing thermally-degradable salts such as $\mathrm{NH}_{4} \mathrm{NO}_{3}$, pure $\mathrm{TiO}_{2}$ monoliths can be simply obtained after heat treatment. The ability to form homogeneous transparent monoliths can be further applied to tailor porous monolithic gels such as aerogels, and to fabricate optoelectrical devices which are currently underway.

\section{Acknowledgement}

The Grant-in-Aid for Scientific Research (No. 20750177 for K. K. and No. 20350094 for K. N.) and the Global COE Program "International Center for Integrated Research and Advanced Education in Materials Science” (No. B-09) both from the Ministry of Education, Culture, Sports, Science and Technology (MEXT), Japan, are acknowledged. Also, partly supported by a Grant for Practical Application of University R\&D Results under the Matching Fund Method from New Energy and Industrial Technology Development Organization (NEDO), Japan.

\section{Reference}

[1] Anderson MA, Gieselmann MJ, Xu Q (1988) J Membrane Sci 39:243-258

[2] Kurganov A, Trüdinger U, Isaeva T, Unger K (1996) Chromatographia 42:217-222

[3] Buchmeiser MR (2001) J Chromatogr A 918:233-266

[4] Asahi R, Morikawa T, Ohwaki T, Aoki K, Taga Y (2001) Science 293:269-271

[5] Khan SUM, Al-Shahry M, Ingler WB (2002) Science 297:2243-2245 
[6] Hoffmann MR, Martin ST, Choi W, Bahnemann DW (1995) Chem Rev 95:69-96

[7] Fujishima A, Honda K (1972) Nature 238:37-38

[8] O’Regan B, Gratzel M. (1991) Nature 353:737-740

[9] Carp O, Huisman CL, Reller A (2004) Prog Solid State Chem 32:33-177

[10] Sakai N, Ebina Y, Takada K, Sasaki T (2004) J Am Chem Soc 126:5851-5858

[11] Kavan L, Kalbac M, Zukalova M, Exnar I, Lorenzen V, Nesper R, Graetzel M (2004) Chem Mater 16:477-485

[12] Kim HS, Gilmer DC, Campbell SA, Polla DL (1996) Appl Phys Lett 69:3860-3862

[13] Wang R, Hashimoto K, Fujishima A, Chikuni M, Kojima E, Kitamura A, Shimohigoshi M, Watanabe T (1997) Nature 388:431-432

[14] Yu JC, Zhang L, Yu J (2002) Chem Mater 14:4647-4653

[15] Hague DC, Mayo MJ (1994) J Am Ceram Soc 77:1957-1960

[16] Negishi N, Iyoda T, Hashimoto K, Fujishima A (1995) Chem Lett 24:841-842

[17] Matsuda A, Kotani Y, Kogure T, Tatsumisago M, Minami T (2000) J. Am Ceram Soc 83:229-231

[18] Kajihara K, Nakanishi K, Tanaka K, Hirao K, Soga N (1998) J Am Ceram Soc 81:2670-2676

[19] Yoldas BE (1980) J Non-Cryst Solids 38:81-86

[20] Mariscal R, Palacios JM, Galan-Fereres M, Fierro JLG (1994) Appl Catal A 116:205-219

[21] Kim WI, Hong IK (2003) J Ind End Chem 9:728-734

[22] Lee JH, Choi SY, Kim CE (1997) J Mater Sci 32:3577-3585

[23] Yoldas BE (1986) J Mater Sci 21:1087-1092

[24] Terabe K, Kato K, Miyazaki H, Yamaguchi S, Imai A, Iguchi Y (1994) J Mater Sci 29:16171622

[25] Konishi J, Fujita K, Nakanishi K, Hirao K (2006) Chem Mater 18:6069-6074

[26] Yao B, Zhang L (1999) J Mater Sci 34:5983-5987

[27] Mir LE, Amlouk A, Elaloui E, Saadoun M, Pierre AC (2008) Mater Sci Eng B 146:69-73

[28] Moriguchi I, Maeda H, Teraoka Y, Kagawa S (1997) Chem Mater 9:1050-1057

[29] Arconada N, Durán A, Suárez S, Portela R, Coronado JM, Sánchez B, Castro Y (2009) Appl Catal B 86:1-7

[30] Wellbrock U, Beier W, Frischat GH (1992) J Non-Cryst Solids 147:350-355

[31] Matijević E, Scheiner P (1978) J Colloid Interface Sci 63:509-524

[32] Attar AS, Ghamsari MS, Hajiesmaeilbaigi F, Mirdamadi S (2008) J Mater Sci 43:1723-1729

[33] Doyle G, Tobias RS (1968) Inorg Chem 7:2484-2488

[34] Kallala M, Sanchez C, Cabane B (1993) Phys Rev E 48:3692-3704

[35] Blanchard J, In M, Schaudel B, Sanchez C (1998) Eur J Inorg Chem 1115-1127

[36] Matijević E, Budnik M, Meites L (1977) J Colloid Interface Sci 61:302-311

[37] Noda LK, de Almeida RM, Probst LFD, Gonçalves NS (2005) J Molecul Catal A 225:39-46

[38] Minero C, Mariella G, Maurino V, Pelizzetti E (2000) Langmuir 16:2632-2641

[39] Calza P, Pelizzeti E, Mogyorósi K, Kun R, Dékány I (2007) Appl Catal 72:314-321

[40] Brinker CJ, Scherer GW (1990) Sol-Gel Science. Academic Press Inc, New York

[41] Allred AL, Rochow EG (1958) J Inorg Nucl Chem 5:264-268 
Scheme Title

Scheme 1 Schematic structure of $\mathrm{Ti}(\mathrm{OPr})_{4}$ chelated by EtAcAc. (a) One equivalent of EtAcAc and (b) Two equivalents of EtAcAc.

Scheme 2 Schematic oligomeric structure of the sol after adding $\mathrm{H}_{2} \mathrm{O}$.

Scheme 3 The anions enable to suppress the hydrolysis by acting as a kind of catalyst with repeating the coordination and dissociation.

Figure Legend

Figure 1 Gelation time of $\mathrm{Ti}(\mathrm{OPr})_{4}$ with various concentration of $\mathrm{NH}_{4} \mathrm{Cl}$. The mixture of 5.0 $\mathrm{mL}$ of $\mathrm{Ti}(\mathrm{OPr})_{4}, 2.5 \mathrm{~mL}$ of EtAcAc, $5.0 \mathrm{~mL}$ of $\mathrm{PrOH}$ and $1.0 \mathrm{~mL}$ of $\mathrm{NH}_{4} \mathrm{Cl}$ aq. was reacted at 40 ${ }^{\circ} \mathrm{C}$.

Figure 2 Gelation time of $\mathrm{Ti}(\mathrm{OPr})_{4}$ at different concentrations of EtAcAc. The mixture of 5.0 $\mathrm{mL}$ of $\mathrm{Ti}(\mathrm{OPr})_{4}$, EtAcAc, $\mathrm{PrOH}$ and $1.0 \mathrm{~mL}$ of $0.2 \mathrm{M} \mathrm{NH}_{4} \mathrm{Cl}$ aq. was reacted at $40{ }^{\circ} \mathrm{C}$. For the amounts of EtAcAc and PrOH, see Table 4.

Figure 3 Gelation time of $\mathrm{Ti}(\mathrm{OPr})_{4}$ at the different concentrations of $\mathrm{H}_{2} \mathrm{O}$. The mixture of 5.0 $\mathrm{mL}$ of $\mathrm{Ti}(\mathrm{OPr})_{4}, 2.5 \mathrm{~mL}$ of EtAcAc, $5.0 \mathrm{~mL}$ of $\mathrm{PrOH}$ and $0.2 \mathrm{M} \mathrm{NH}_{4} \mathrm{Cl}$ aq. was reacted at $40{ }^{\circ} \mathrm{C}$.

Figure 4 Appearance of the obtained gels prepared with different amount of $\mathrm{NH}_{4} \mathrm{Cl}$. (a) without $\mathrm{NH}_{4} \mathrm{Cl}$, (b) $0.25 \mathrm{~mol} \%$ of $\mathrm{NH}_{4} \mathrm{Cl}$ (relative to $\mathrm{Ti}(\mathrm{OPr})_{4}$ ), (c) $0.50 \mathrm{~mol} \%$ of $\mathrm{NH}_{4} \mathrm{Cl}$ and (d) 0.75 mol \% of $\mathrm{NH}_{4} \mathrm{Cl}$.

Figure 5 The TG-DTA curves of the dried gels prepared with different amounts of EtAcAc. The mixture of $5.0 \mathrm{~mL}$ of Ti(OPr) $)_{4}$, EtAcAc, $\mathrm{PrOH}$ and $1.0 \mathrm{~mL}$ of $0.2 \mathrm{M} \mathrm{NH}_{4} \mathrm{Cl}$ aq. was reacted at $40{ }^{\circ} \mathrm{C}$. (a) $1.0 \mathrm{~mL}$ of EtAcAc, (b) $2.5 \mathrm{~mL}$ of EtAcAc and (c) $5.0 \mathrm{~mL}$ of EtAcAc.

Figure 6 The XRD patterns of the dried gels and the samples heat-treated from $300{ }^{\circ} \mathrm{C}$ to $700{ }^{\circ} \mathrm{C}$ for $5 \mathrm{~h}$. 
Figure 7 The FT-IR spectra of the dried gels and the samples heat-treated from $200{ }^{\circ} \mathrm{C}$ to $700{ }^{\circ} \mathrm{C}$ for $5 \mathrm{~h}$.

Tables

Table 1 Appearance of resultant titania gels with various mineral salts. The mixture of $5.0 \mathrm{~mL}$ of $\mathrm{Ti}(\mathrm{OPr})_{4}, 2.5 \mathrm{~mL}$ of EtAcAc, $5.0 \mathrm{~mL}$ of $\mathrm{PrOH}$ and $1.0 \mathrm{~mL}$ of $0.2 \mathrm{M}$ aqueous solution of salt was reacted at $40^{\circ} \mathrm{C}$.

\begin{tabular}{|c|c|}
\hline Mineral salts & Gel appearance \\
\hline $\mathrm{NH}_{4} \mathrm{~F}$ & Opaque \\
\hline $\mathrm{NH}_{4} \mathrm{Cl}$ & Transparent \\
\hline $\mathrm{NH}_{4} \mathrm{NO}_{3}$ & Transparent \\
\hline$\left(\mathrm{NH}_{4}\right)_{2} \mathrm{CO}_{3}$ & Opaque \\
\hline $\mathrm{CH}_{3} \mathrm{COONH}_{4}$ & Opaque \\
\hline$\left(\mathrm{NH}_{4}\right)_{2} \mathrm{VO}_{3}$ & Opaque \\
\hline$\left(\mathrm{NH}_{4}\right)_{2} \mathrm{HPO}_{4}$ & Opaque \\
\hline $\mathrm{KCl}$ & Transparent \\
\hline $\mathrm{KBr}$ & Transparent \\
\hline KI & Transparent \\
\hline $\mathrm{KNO}_{3}$ & Transparent \\
\hline $\mathrm{K}_{2} \mathrm{SO}_{4}$ & Opaque \\
\hline $\mathrm{CH}_{3} \mathrm{COOK}$ & Opaque \\
\hline $\mathrm{K}_{2} \mathrm{CO}_{3}$ & Opaque \\
\hline $\mathrm{CaCl}_{2}$ & Transparent \\
\hline $\mathrm{AlCl}_{3}$ & Transparent \\
\hline $\mathrm{AlPO}_{4}$ & Opaque \\
\hline $\mathrm{FeCl}_{3}$ & Transparent \\
\hline $\mathrm{YCl}_{3}$ & Transparent \\
\hline $\mathrm{LaCl}_{3}$ & Transparent \\
\hline $\mathrm{CeCl}_{3}$ & Transparent \\
\hline
\end{tabular}


Table 2 Gelation time of $\mathrm{Ti}(\mathrm{OPr})_{4}$ in the presence of various chloride salts at the same concentration of chloride anions. The mixture of $5.0 \mathrm{~mL}$ of Ti(OPr $)_{4}, 2.5 \mathrm{~mL}$ of EtAcAc, $5.0 \mathrm{~mL}$ of $\mathrm{PrOH}$ and aqueous solution of salt was reacted at $40{ }^{\circ} \mathrm{C}$. The molar ratio of $\mathrm{Ti}(\mathrm{OPr})_{4}: \mathrm{H}_{2} \mathrm{O}: \mathrm{Cl}^{-}$ was 1:2.91:0.01.

\begin{tabular}{cc}
\hline Mineral salt & Gelation time/min \\
\hline $\mathrm{NH}_{4} \mathrm{Cl}$ & 132 \\
$\mathrm{KCl}$ & 127 \\
$\mathrm{CaCl}_{2}$ & 133 \\
$\mathrm{AlCl}_{3}$ & 140 \\
\hline
\end{tabular}

Table 3 Gelation time of $\mathrm{Ti}(\mathrm{OPr})_{4}$ in the presence of various potassium salts at the same concentration of anions. The mixture of $5.0 \mathrm{~mL}$ of $\mathrm{Ti}(\mathrm{OPr})_{4}, 2.5 \mathrm{~mL}$ of EtAcAc, $5.0 \mathrm{~mL}$ of PrOH and aqueous solution of salt was reacted at $40{ }^{\circ} \mathrm{C}$. The molar ratio of $\mathrm{Ti}(\mathrm{OPr})_{4}: \mathrm{H}_{2} \mathrm{O}$ :anion was 1:2.91:0.01.

\begin{tabular}{cc}
\hline Mineral salts & Gelation time/min \\
\hline $\mathrm{KNO}_{3}$ & 136 \\
$\mathrm{KCl}$ & 127 \\
$\mathrm{KBr}$ & 115 \\
$\mathrm{KI}$ & 98 \\
\hline
\end{tabular}

Table 4 Gelation time of $\mathrm{Ti}(\mathrm{OPr})_{4}$ at different concentrations of EtAcAc. The mixture of 5.0 $\mathrm{mL}$ of $\mathrm{Ti}(\mathrm{OPr})_{4}$, EtAcAc, $\mathrm{PrOH}$ and $1.0 \mathrm{~mL}$ of $0.2 \mathrm{M} \mathrm{NH}_{4} \mathrm{Cl}$ aq. was reacted at $40{ }^{\circ} \mathrm{C}$.

\begin{tabular}{ccc}
\hline EtAcAc/mL & PrOH/mL & Gelation time $/ \mathrm{min}$ \\
\hline 2.0 & 5.5 & 30 \\
2.5 & 5 & 80 \\
3.0 & 4.5 & 160 \\
3.5 & 4 & 320 \\
4.0 & 3.5 & 420 \\
4.5 & 3 & 600
\end{tabular}


5.0

6.0

7.0
2.5

1.5

0.5
730

870

840 


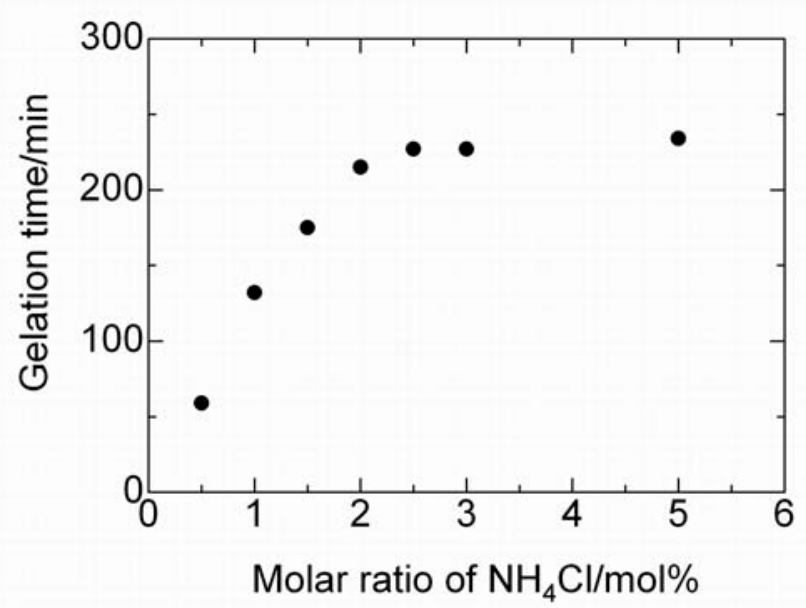

Figure 1

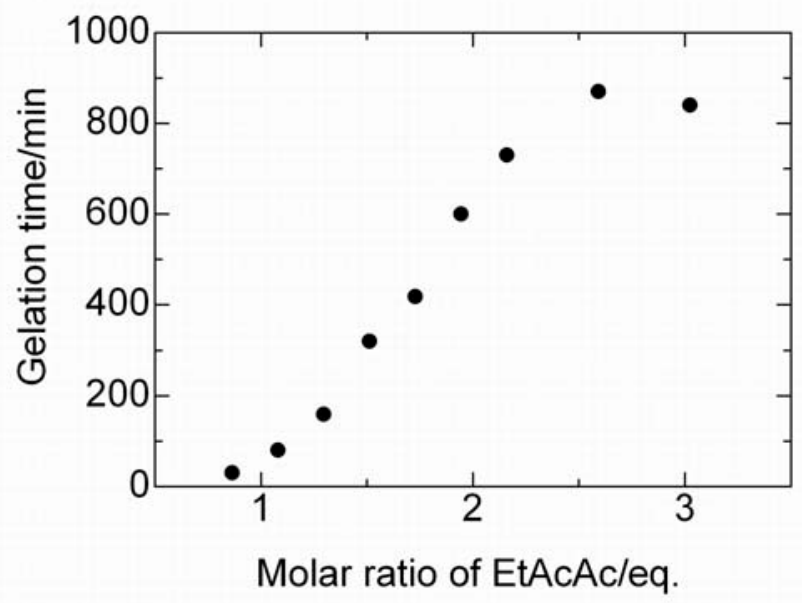

Figure 2

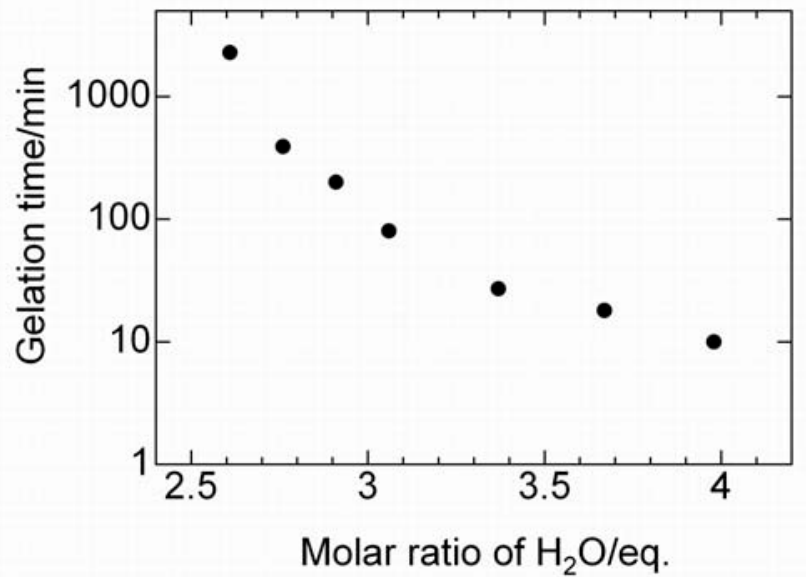

Figure 3 


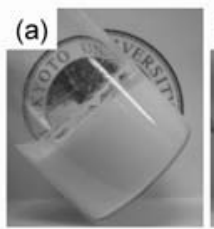

$\mathrm{No} \mathrm{NH}_{4} \mathrm{Cl}$

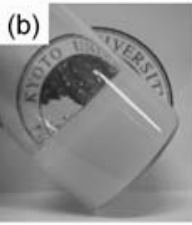

$0.25 \mathrm{~mol} \% \mathrm{NH}_{4} \mathrm{Cl} \quad 0.50 \mathrm{~mol} \% \mathrm{NH}_{4} \mathrm{Cl} \quad 0.75 \mathrm{~mol} \% \mathrm{NH}_{4} \mathrm{Cl}$

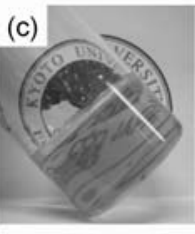

(d)

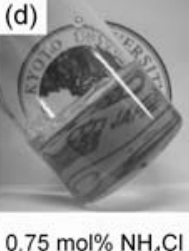

Figure 4

(a) EtAcAc $1.0 \mathrm{~mL}$

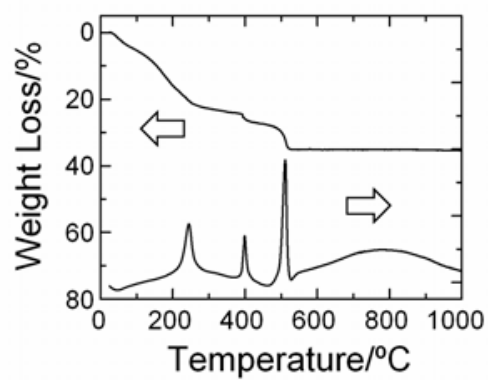

(b) EtAcAc $2.5 \mathrm{~mL}$

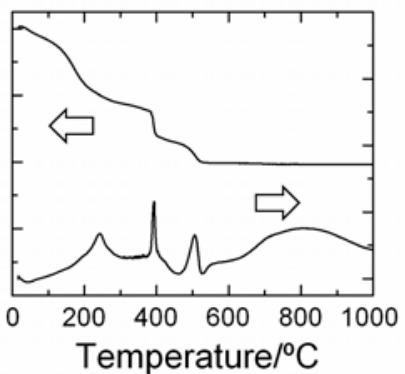

Figure 5

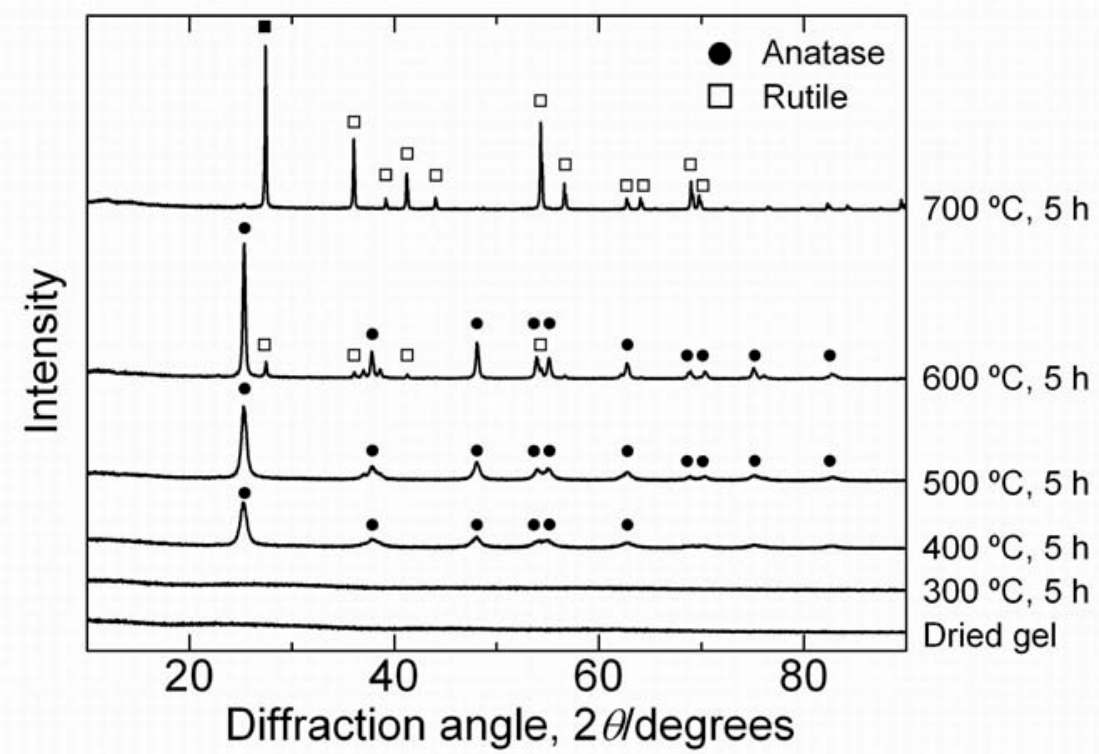

Figure 6 


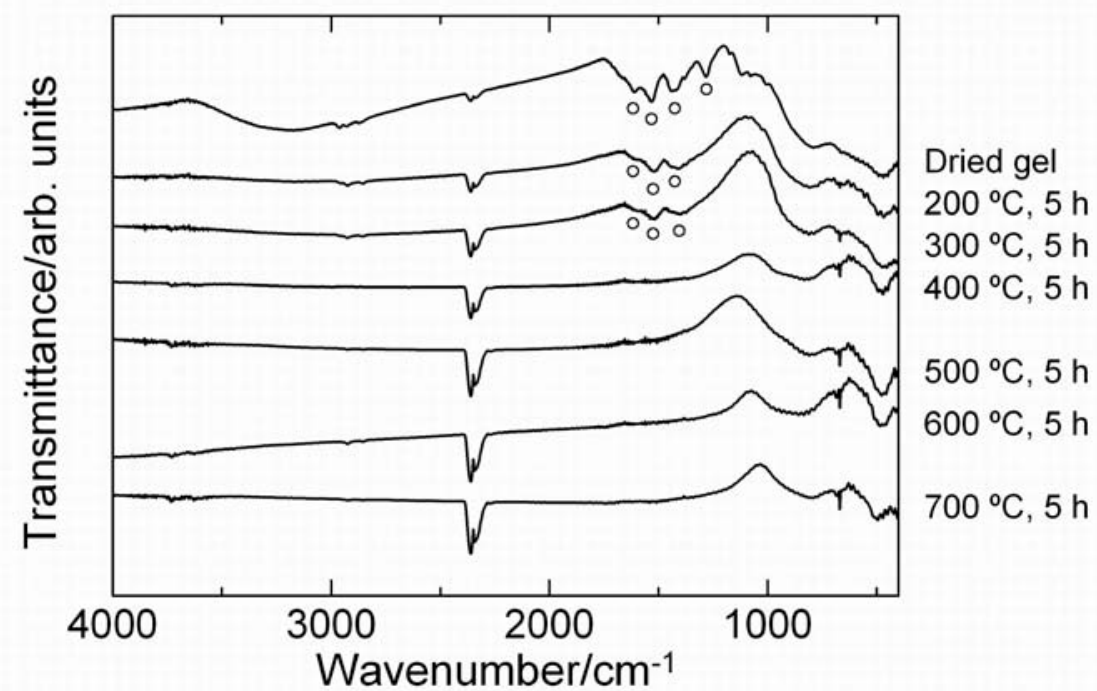

Figure 7

(a)<smiles></smiles><smiles>CCCO[Te](OCC)(OCC)OC(=O)CC</smiles>

(b)

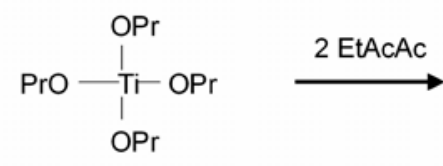<smiles>CCO[P+]1(OCC)OC(=O)C=C(C)O1</smiles>

Scheme 1 


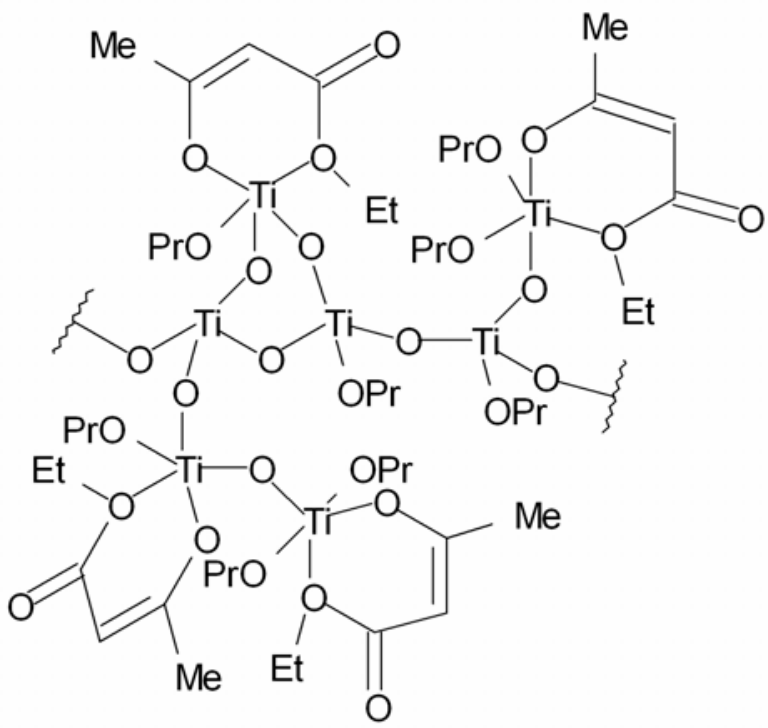

Scheme 2
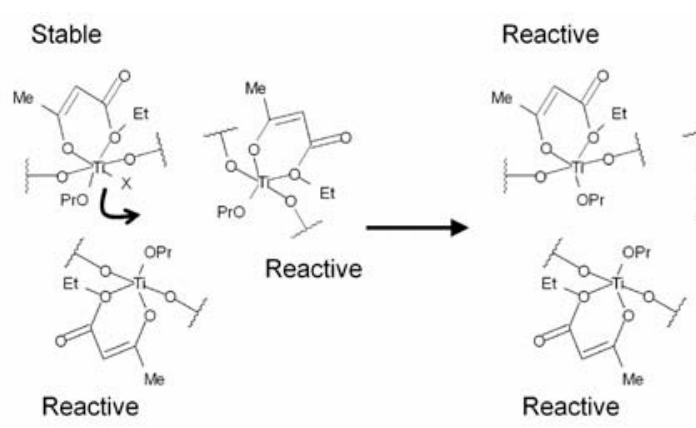

Reactive

$\mathrm{X}^{-}=\mathrm{Cl}^{-}, \mathrm{Br}, \mathrm{I}-, \mathrm{NO}_{3}^{-}$

Scheme 3 